\title{
BMJ Open Nutritional indicators for gastrointestinal symptoms in female runners: the 'Marikenloop study'
}

Dominique S M ten Haaf, ${ }^{1}$ Maarten $\mathrm{P}$ van der Worp, ${ }^{1,2}$ Hans M M Groenewoud, ${ }^{1,3}$ Susanne Leij-Halfwerk, ${ }^{2}$ Maria W G Nijhuis-van der Sanden, ${ }^{1}$ André L M Verbeek, ${ }^{1,3} \mathrm{~J}$ Bart Staal ${ }^{1,2}$

To cite: ten Haaf DSM, van der Worp MP,

Groenewoud HMM, et al.

Nutritional indicators for gastrointestinal symptoms in female runners:

the 'Marikenloop study'. BMJ Open 2014;4:e005780.

doi:10.1136/bmjopen-2014005780

- Prepublication history for this paper is available online. To view these files please visit the journal online (http://dx.doi.org/10.1136/ bmjopen-2014-005780).

Received 4 June 2014 Revised 13 July 2014 Accepted 14 July 2014

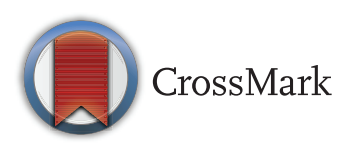

${ }^{1}$ Radboud University Medical Centre, Scientific Institute for Quality of Healthcare, Nijmegen, The Netherlands ${ }^{2}$ HAN, University of Applied Sciences Nijmegen, Institute of Health Studies, Nijmegen, The Netherlands

${ }^{3}$ Department for Health Evidence, Radboud University Medical Centre, Nijmegen, The Netherlands

Correspondence to Dr J Bart Staal; bart.staal@radboudumc.nl

\section{ABSTRACT}

Objectives: Among runners the reported prevalence of exercise-induced gastrointestinal (Gl) symptoms is high $(25 \%-83 \%)$. We aimed to investigate the prevalence of Gl symptoms in women during a $5-10 \mathrm{~km}$ run in general and to explore the association between nutritional intakes and $\mathrm{Gl}$ symptoms.

Setting: As part of the Marikenloop-study (a cohort study to identify predictor variables of running injuries), a cross-sectional questionnaire was distributed in interested runners of the '2013 Marikenloop'.

Participants: 433 female runners filled in the questionnaire.

Primary and secondary outcome measures: The primary outcome measure was the frequency of running-related $\mathrm{Gl}$ symptoms during running in general and during the last (training) run. Furthermore, dietary intake was determined before and during this run. Secondary outcome measures were several demographic and anthropometric variables.

Results: During running in general, $40 \%$ of the participants suffered from Gl symptoms and during their last run, $49 \%$. The Gl symptoms side ache, flatulence, urge to defecate and regurgitation and/or belching were most commonly reported. Lower age ( $\mathrm{OR}=0.98,95 \% \mathrm{Cl} 0.96$ to 1.00$)$, minor running experience (OR=3.1, $95 \% \mathrm{Cl} 1.7$ to 5.7 ), higher body mass index ( $\mathrm{OR}=1.1,95 \% \mathrm{Cl} 1.0$ to 1.2 ), consuming carbohydrate-containing drinks during running (OR=10.5, 95\% $\mathrm{Cl} 1.4$ to 80.3 ) and experiencing GI symptoms during running in general $\mathrm{OR}=5.0,95 \% \mathrm{Cl}$ 3.2 to 7.8 ) significantly contributed to $\mathrm{Gl}$ symptoms during the last run in the logistic regression analysis. In contrast, time of eating and carbohydrate-containing drinks consumed prior to the run were not related to GI symptoms.

Conclusions: In conclusion, the current study confirms the high prevalence of Gl symptoms in female runners. Several predictor variables contributed to the GI symptoms but more research is needed to specify the effects of prerunning eating and carbohydratecontaining drinks on $\mathrm{Gl}$ symptoms during running.

Trial registration number: Marikenloop study 2013: 50-50310-98-156 (ZonMw).

\section{Strengths and limitations of this study}

- Running-induced gastrointestinal (GI) symptoms often occur. By indicating which risk factors induce GI symptoms, adjustments can be made and Gl symptoms might be minimised.

- This study gives more clarity about several demographic and anthropometric variables and two possible dietary factors that have been proposed to induce Gl symptoms: prerunning eating and consumption of carbohydrate-containing beverages.

- A limitation of this study is the cross-sectional design.

\section{INTRODUCTION}

Emerging research indicates that physical activity is beneficial for the gastrointestinal (GI) tract. ${ }^{1-3}$ However, strenuous physical exercise such as running can also induce upper and lower GI tract symptoms. ${ }^{1-3}$ Prevalence of exercise-induced GI symptoms in runners has been reported to vary from $25 \%$ to $83 \%$ during or after a run. ${ }^{14-13}$

Exercise-induced GI symptoms seem to be caused predominantly by increased sympathetic nervous system activity that redistributes blood flow during exercise from the splanchnic organs to the working skeletal muscles, heart, lung and brain. ${ }^{114}$ This often leads to GI ischaemia, which may result in GI symptoms. ${ }^{1}{ }^{15}$ GI symptoms are more likely to occur in runners as compared with cyclists or swimmers ${ }^{911} 131617$ probably because of the constant pounding motion of running, which may induce stress to the abdominal organs. ${ }^{16}$ Therefore, GI symptoms might be a reason for people to quit running. ${ }^{7}$ In the past decades more women have started running in the Netherlands. ${ }^{18}$ In several investigations, a higher incidence of running-related GI problems was observed in women compared with 
men. ${ }^{1} \quad 5-912$ Therefore, GI symptoms may become an increasing problem.

The occurrence of exercise-related GI symptoms may further be higher with lower age,${ }^{6}{ }^{10}$ less running experience, ${ }^{7}{ }^{10}$ longer duration of exercise ${ }^{6} 81^{19}$ and an increased BMI. ${ }^{20}$

Several possible dietary factors have been hypothesised as inducing GI symptoms in athletes. For example, dehydration, ${ }^{8} 2122$ high fat, fibre and protein intakes (solid food), eating before exercise and hypertonic solutions. ${ }^{13}$ However, data on the association between exerciseinduced GI symptoms and prerunning eating and/or hypertonic solutions are scarce.

The American College of Sports Medicine stated that the pre-exercise meal should be consumed $3-4 \mathrm{~h}$ before exercise and a smaller meal or snack should be consumed $2-4 \mathrm{~h}$ before exercise. ${ }^{23}$ However, minimal research has been performed on the effect of the timing of the pre-exercise meal and snack on GI symptoms. In 1989, Rehrer $e t a l^{8}$ found no association between the time of the last meal and GI disturbances, but almost all athletes ate $3-5 \mathrm{~h}$ before the race. They further showed that individuals who consumed solid food closer to the start vomited more frequently or had a higher vomiting urge during a triathlon. ${ }^{13}$ Another study also found that nausea exacerbated when exercise was conducted immediately after eating. ${ }^{24}$

Rehrer $e t a l^{13}$ also showed that individuals who consumed hypertonic beverages had to vomit more and/or had stomach cramps. van Nieuwenhoven et $a l^{1625}$ found conflicting evidence about the effect of isotonic sports drinks compared with water on incidences of GI symptoms and GI variables. Peters $e t a l^{7}$ found that water intake before competition was related to more upper GI symptoms. It is not clear what amount of fluid or sugar contributes to GI symptoms.

The objective of this study was to investigate the prevalence of upper and lower GI symptoms in general during running and during the last run in female athletes who participated in the '2013 Marikenloop', a run of 5 and $10 \mathrm{~km}$ for women in the Netherlands. Furthermore, we aimed at exploring the association between the dietary intake of female runners' prerunning and GI symptoms during running.

\section{METHODS}

\section{Subjects}

Study participants consisted participants aged $\geq 18$ years who registered for the '2013 Marikenloop', a run specifically for women, which was held on 26 May 2013 in Nijmegen, the Netherlands. On 12 March, 13000 women signed up for the '2013 Marikenloop', which is the largest run of the Netherlands for women with distances of either 5 or $10 \mathrm{~km}$. Via social media and the newsletter of the 'Marikenloop' organisation, female runners were informed about the Marikenloop study. The runners from the '2013 Marikenloop' could sign up for the Marikenloop study online from 8 to 24 March. All participants first signed the informed consent. Participants were informed that the objective of the research was to identify predictor variables for running injuries.

\section{Study design}

The present study was part of the 'Marikenloop study', which is a prospective cohort study aimed at identifying predictor variables for running injuries. To arrive at the study sample size we assumed 8 events per variable, an injury incidence rate of $30 \%$ and 15 independent predictors resulting in a required sample size of at least 360 participants. ${ }^{26}{ }^{27}$ The study also consisted of a crosssectional questionnaire to obtain data on GI symptoms and dietary information, as well as several demographic and anthropometric data. The questionnaire was distributed via email on 24 March. Participants received two reminders if needed and were allowed to complete the questionnaire until 12 April 2013.

\section{Questionnaire}

From the total online questionnaires, several demographic and anthropometric characteristics and questions about running were used for the present study. Furthermore, questions were developed about the presence of GI symptoms and a dietary recall in which the timing of the prerunning meal and snack and of drinking around the last run was detected.

The participants were asked to estimate their frequency of running-related GI symptoms during running in general by indicating on a four-point Likert scale whether symptoms generally occurred either never, sometimes, occasionally or frequently during running. Symptoms surveyed included the upper GI tract symptoms of chest pain, nausea, regurgitation and/or belching, heartburn, feeling of fullness and vomiting. The lower GI tract symptoms questioned were bloating, abdominal cramps, flatulence, urge to defecate, diarrhoea, constipation and rectal bleeding and/or haematuria. Side ache was also included as a lower GI symptom. ${ }^{8}$

Participants were then asked to indicate the presence of these 14 GI symptoms (yes/no) during their last run in which they prepared for the 'Marikenloop' around 2 months before the actual 'Marikenloop' run. Furthermore, participants were asked what the time interval between their last food intake before the start of their last run was. It was possible to indicate that they had run on an empty stomach in the morning.

Drinking habits around the last run were inquired by asking what the participants drank before their last run. For several sport drinks, pictures were used and for soda, juices, alcoholic drinks and with the option 'other drinks' a clarification was asked to indicate which drink it was exactly. Per drink, participants were asked when they drank it (1-4 h before running, within $1 \mathrm{~h}$ before running, during running, within $1 \mathrm{~h}$ after running, 1-4 h after running). Finally, participants had to 
estimate how much they drank in these five time frames. Pictures were used to indicate what normal portion sizes of different glasses and bottles are. Carbohydrate content of the various beverages that were consumed was determined using manufacturers' specifications. A drink was considered hypotonic if it consisted of maximal $6 \mathrm{~g} / 100 \mathrm{~mL}$ carbohydrates. If the drink consisted of $6-8 \mathrm{~g} / 100 \mathrm{~mL}$ carbohydrates, it was considered isotonic and with more than $8 \mathrm{~g} / 100 \mathrm{~mL}$ carbohydrates, it was called hypertonic. ${ }^{28}$ If hypotonic and hypertonic drinks were drunk at a specific time frame, the drink was rated as isotonic. When an equal amount of hypotonic and isotonic drinks or isotonic and hypertonic drinks was consumed simultaneously, the highest category was chosen. If however, one of two sorts of drinks was consumed more at a specific time frame, that category was chosen (eg, if two hypotonic and one isotonic drink was consumed in the same time frame, hypotonic was chosen).

\section{Data analysis}

Statistical analysis was performed using SPSS for Windows (V.19.0; SPSS Inc, Chicago, Illinois, USA). and a GI symptom was considered present during running in general (a positive response) when a participant answered 'occasionally' or 'frequently' to the question about the frequency of GI symptoms during running. A GI symptom was considered absent (a negative response) when 'never' or 'sometimes' were indicated. GI symptoms were considered present during the last run when participants indicated 'yes' for a symptom on the list.

Analysis of normal distribution (Shapiro-Wilk test and normal QQ-plot) was performed for continuous variables: age, BMI, timing of pre-running meal and/or snack, amount of drink $(\mathrm{mL})$ and by dividing the selfmeasured waist circumference $(\mathrm{cm})$ with the reported height $(\mathrm{cm})$, the waist-to-hip ratio (WHR) was obtained.

Mean baseline differences between participants with and without GI symptoms were determined using an independent samples t-test to detect possible confounders.
To compare characteristics between the runners with and without GI symptoms during their last run twosample $\mathrm{t}$ tests were performed for continuous variables. In terms of categorical variables $\chi^{2}$ tests or a Fisher's exact test were conducted.

Significant associations were identified with multivariable binary logistic regression analysis (forced entry method). Nutritional variables (ie, timing of the prerunning meal/snack, running on an empty stomach, amount drink (mL) consumed and type of drink) were hypothesised to be related to GI symptoms during the last run and possible confounders were adjusted for in the model. To check for collinearity between the different predictor variables we calculated the variance inflation factors (VIF). If multicollinearity was present the variable which was considered most relevant, was used in the multivariable analyses. Risk model calibration was assessed by the Hosmer-Lemeshow goodness-of-fit test. $\mathrm{p}$ Values $\leq 0.05$ were accepted as statistically significant.

\section{RESULTS}

\section{Subjects}

On 12 April, 435 of the 472 participants filled out the baseline questionnaire of the 'Marikenloop study' (drop-out rate: $8 \%$ ). The average age of the drop-out group was $38.4 \pm 12.4(\mathrm{SD})$ and did not significantly differ from the group who filled out the questionnaire $(p=0.90)$. Two questionnaires were excluded because the participant was male $(\mathrm{n}=1)$ and not $\geq 18$ years old $(\mathrm{n}=1)$.

The baseline characteristics of the included 433 participants are presented in table 1 . The total group had an average body mass index (BMI) of $23.2 \mathrm{~kg} / \mathrm{m}^{2}$ and a WHR of 0.80 . Two hundred and ten participants sustained $\geq 1$ GI symptom during their last run. Significant differences between the groups with and without symptoms during their last run were found for age, body weight and BMI.

Table 1 Baseline characteristics of the Marikenloop runners

\begin{tabular}{|c|c|c|c|}
\hline \multirow[b]{2}{*}{ Variable } & \multirow{2}{*}{$\begin{array}{l}\text { Total group } \\
n=433^{*}\end{array}$} & \multicolumn{2}{|c|}{$\geq 1$ GI symptoms during their last run } \\
\hline & & Yes $\mathrm{n}=210^{*}$ & No $n=223^{*}$ \\
\hline Age (year)† & $38.6 \pm 11.5$ & $36.8 \pm 11.5$ & $40.4 \pm 11.2$ \\
\hline Body weight $(\mathrm{kg}) \dagger$ & $67.0 \pm 10.6$ & $68.8 \pm 12.3$ & $65.3 \pm 8.5$ \\
\hline Height $(\mathrm{cm})$ & $169.8 \pm 6.3$ & $170.1 \pm 6.6$ & $169.5 \pm 5.9$ \\
\hline BMI $\left(\mathrm{kg} / \mathrm{m}^{2}\right) \dagger$ & $23.2 \pm 2.9$ & $23.6 \pm 3.0$ & $22.7 \pm 2.7$ \\
\hline Waist circumference (cm) & $79.7 \pm 7.9 \ddagger$ & $80.6 \pm 7.7 \S$ & $79.0 \pm 8.19$ \\
\hline WHR & $0.80 \pm 0.06 \ddagger$ & $0.81 \pm 0.05 \S$ & $0.80 \pm 0.06\rceil$ \\
\hline \multicolumn{4}{|c|}{$\begin{array}{l}\text { *Data represent mean } \pm S D \text {. } \\
\dagger \text { Significant difference between group with and without GI symptoms during their last run }(p<0.001) \text {. } \\
\ddagger n=245 \text {. } \\
\S n=109 \text {. } \\
\text { ๆn } n=136 \text {. } \\
\text { BMI, body mass index; GI, gastrointestinal; WHR, waist-to-hip ratio. }\end{array}$} \\
\hline
\end{tabular}


Table 2 Prevalence of at least $1 \mathrm{Gl}$ symptom during running in general and during their last run

\begin{tabular}{|c|c|c|c|c|c|c|}
\hline & \multicolumn{2}{|c|}{$\geq 1$ Gl symptoms* } & \multicolumn{2}{|c|}{$\geq 1$ upper Gl symptoms } & \multicolumn{2}{|c|}{$\geq 1$ lower Gl symptom* } \\
\hline & $\mathbf{n}$ & $\operatorname{Pr}(95 \% \mathrm{Cl})$ & $\mathbf{n}$ & $\operatorname{Pr}(95 \% \mathrm{Cl})$ & $\mathbf{n}$ & $\operatorname{Pr}(95 \% \mathrm{Cl})$ \\
\hline During run in general & 171 & 0.40 (0.35 to 0.44$)$ & 67 & $0.16(0.12$ to 0.19$)$ & 155 & $0.36(0.31$ to 0.40$)$ \\
\hline During last run & 210 & 0.49 (0.44 to 0.53$)$ & 82 & $0.19(0.15$ to 0.23$)$ & 181 & $0.42(0.37$ to 0.46$)$ \\
\hline
\end{tabular}

*Significant difference between during run in general and during last run $(\mathrm{p}=0.00)$

GI, gastrointestinal; Pr, prevalence.

\section{Gl symptoms}

The total prevalence of experiencing at least one GI symptom during running in general was $40 \%$, while $49 \%$ of the participants experienced at least one GI symptom during their last run ( $\mathrm{p}=0.00$; see table 2$)$. Fifty-four per cent who had GI symptoms during running in general experienced more than one symptom. During the last run, this percentage was $42 \%$. As shown in table 2, during running in general, significantly more lower GI symptoms occurred than upper GI symptoms $(0.36(0.31$ to 0.40$), 0.16(0.12$ to 0.19$)$, respectively) just like during the last run $(0.42$ (0.37 to 0.46$), 0.19$ (0.15 to $0.23)$, respectively).

For all GI symptoms, except 'urge to defecate' and 'constipation', more participants suffered from these symptoms during their last run than during running in general (see figure 1). Significant differences between running in general and the last run were found for 'chest pain', 'vomiting' and 'rectal bleeding and/or haematuria' $(\mathrm{p} \leq 0.05)$. The most reported GI symptoms were 'side ache', 'flatulence', 'urge to defecate' and 'regurgitation and/or belching' for running in general and the last run.

\section{Eating and drinking habits before and during last run}

Forty-six women (11\%) ran during their last run on empty stomach. The other participants $(n=387)$ ate their prerunning meal $103.5 \pm 69.9 \mathrm{~min}$ (range 5-360 min) before the run. A snack was consumed $85.3 \pm 62.9$ min (range 5-270 $\mathrm{min})$ before the run $(\mathrm{n}=250)$.

As shown in figure 2, most drinks consumed were hypotonic drinks, a few drank isotonic drinks and hypertonic drinks were the least popular. Most participants drank $1-4 \mathrm{~h}$ before running (70\%). Within $1 \mathrm{~h}$ before running, $63 \%$ drank something. During their run only a few participants drank something (10\%). Between 1and $4 \mathrm{~h}$ before their run $279.4 \pm 234.0 \mathrm{~mL}$ was consumed, within $1 \mathrm{~h}$ before the run $151.7 \pm 114.5 \mathrm{~mL}$ and during $28.2 \pm 87.5 \mathrm{~mL}$.

\section{Risk indicator analyses}

Female runners who experienced at least one GI symptom during their last run had a significantly lower age of on average 3.6 years, an on overage 0.9 higher BMI, included $37 \%$ more participants who experienced GI symptoms in general and had less running experience in months $(\mathrm{p}=0.00)$ than participants without GI symptoms (see table 3). From the eating-related variables and drinking-related variables, female runners with symptoms drank on overage $47.9 \mathrm{~mL}$ more $1-4 \mathrm{~h}$ before running $(p \leq 0.05)$ and running on an empty stomach was correlated with GI symptoms during the last run. From the group who experienced GI symptoms, less people ran on an empty stomach than the group without GI symptoms during their last run $(p=0.023)$. Isotonic and hypertonic drinks and $30-40 \mathrm{~km}$ a week and $>40 \mathrm{~km}$ per average week were pooled, because counts were $<10$.

\section{Multivariable logistic regression}

Multicollinearity was present between the possible predictors of upper and lower GI symptoms and total GI symptoms in general. Since GI symptoms in general include upper and lower GI symptoms, this variable was
Figure 1 Participants who reported gastrointestinal (Gl) symptoms during running in general and $\mathrm{Gl}$ symptoms during their most recent run (\%). Dark bars represent the percentage during running in general with a positive response (sum of 'occasionally' and 'frequently' responses divided by the total number of responses). Striped bars represent the positive response 'yes' divided by the total number of responses during the most recent run.

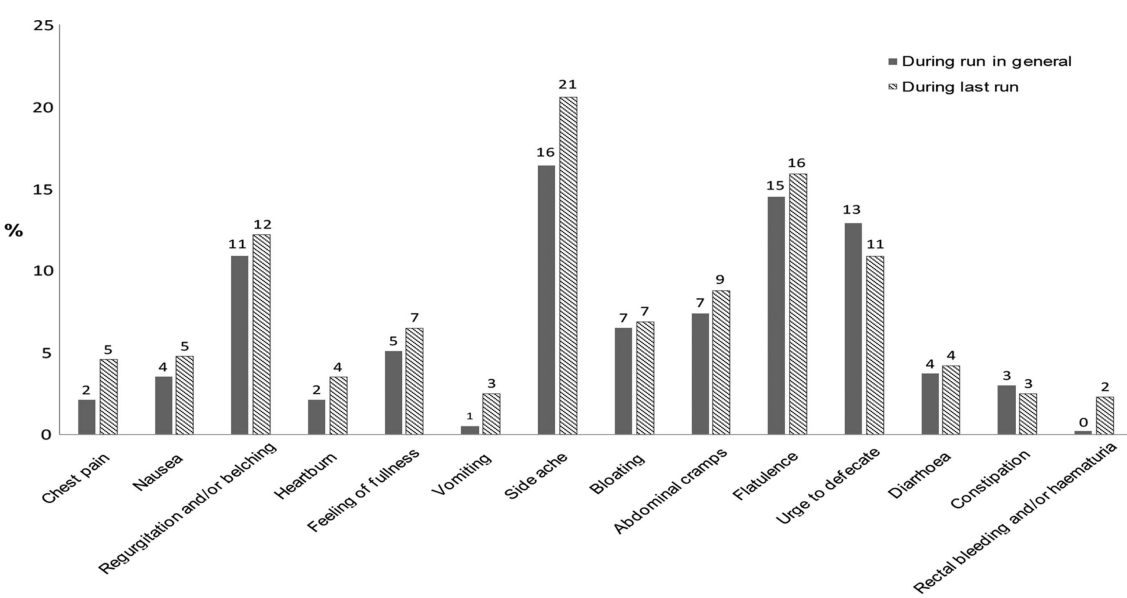


Figure 2 Sort of drinks consumed prior and during most recent run (n).

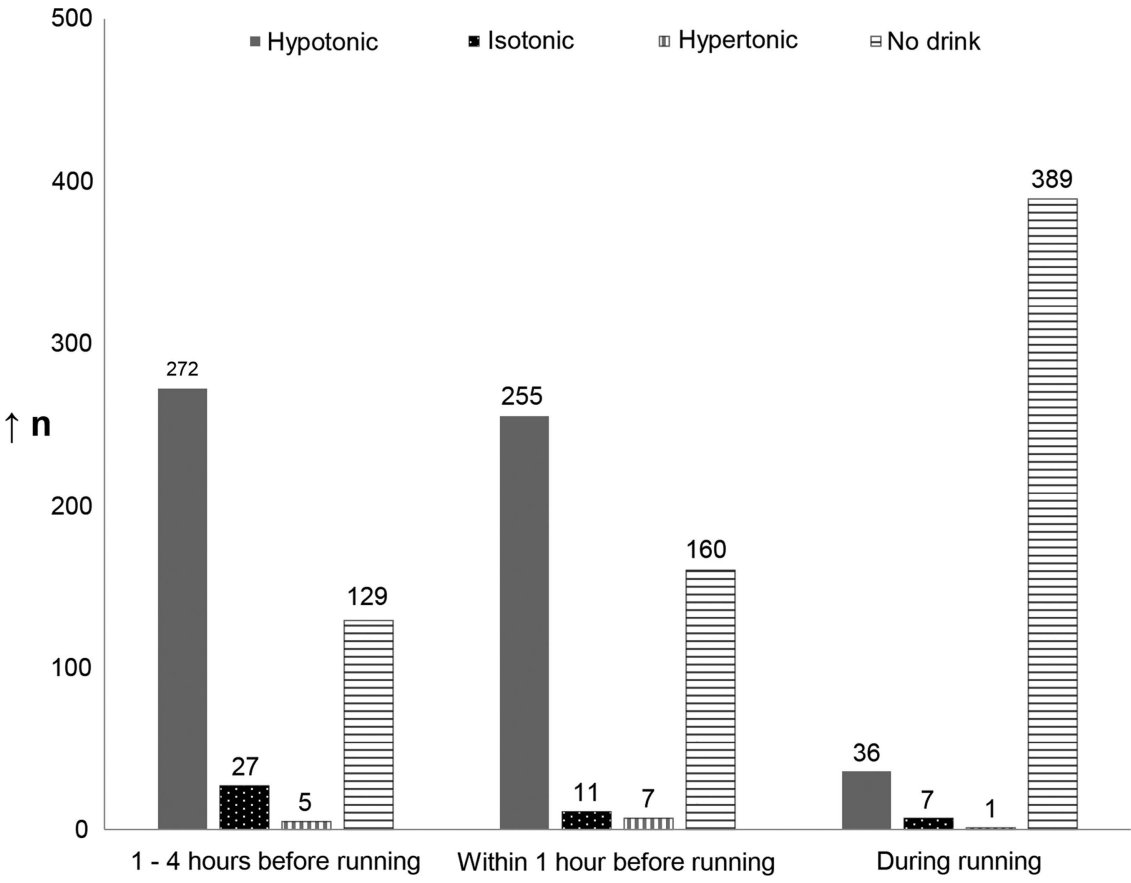

evaluated, next to all the other predictor variables, by multiple logistic regression analyses (see table 4). The drinking of isotonic and/or hypertonic drinks compared with no drinks during running proved to have the largest positive predictive value for running-related GI symptoms and was associated with 10.5-fold increased odds of developing GI symptoms during the last run (95\% CI 1.4 to 80.3$)$. The prevalence of GI symptoms in general showed an odds of 5.0 (95\% CI 3.2 to 7.8). Furthermore, a running experience of 3-12 months compared with more than 12 months increased the odds by 3.1 (95\% CI 1.7 to 5.7). A higher age was slightly protective for suffering from GI symptoms during the last run $(\mathrm{OR}=0.98,95 \%$ CI 0.96 to 1.0$)$. Finally, a higher BMI of 1 unit was associated with GI symptoms during the last run $(\mathrm{OR}=1.1,95 \%$ CI 1.0 to 1.2$)$.

\section{DISCUSSION}

In runners exercise-induced GI symptoms are a problem. In this study $40 \%$ suffered from GI symptoms during running in general and the prevalence during the last run was $49 \%$. The GI symptoms 'side ache', 'flatulence', 'urge to defecate' and 'regurgitation and/ or belching' were most commonly reported. Lower age, more running experience, higher BMI, consuming carbohydrate-containing drinks during running and prevalence of total GI symptoms during running in general were significantly related to GI symptoms during the last run.

We found that $40 \%$ of the female runners suffered from GI symptoms during running in general. This is slightly lower than earlier reported prevalences of GI symptoms during running in general (between $50 \%$ and $54 \%) .^{4711}$ Several articles detected the prevalence of
GI symptoms at a specific run, which varied between $25 \%$ and $52 \% .^{5} 81012 \quad 13$ In accordance with these numbers, our participants indicated that during their last run $49 \%$ experienced GI symptoms. The higher amount of experienced GI symptoms during the most recent run compared with running in general might be caused by survey and recall bias.

It has been suggested that the distance of a run influences the prevalence of GI symptoms. ${ }^{6} 829$ The exact distances of the last run were not detected in our study but no difference was found between women who were training for a 5 or $10 \mathrm{~km}$ run on the day of the 'Marikenloop'. However, the mentioned GI symptoms in the articles are quite severe and might occur more during a longer run and therefore may not be very prevalent in our participants.

The protective effect of higher age shown in table 4 on GI symptoms has been reported previously. ${ }^{6} 91030$ In younger people more splanchnic vasoconstriction occurs because of more or a better response to catecholamines. This leads to reduced oxygen supply, which may result in GI symptoms. ${ }^{1} 10 \quad 15 \quad 2230$ Also, higher age is often accompanied with more running experience. ${ }^{8} 31$ This association between running experience and less GI symptoms was found in several studies, ${ }^{7} 91032$ and corresponds with our results although we should be cautious since no linear relationship was found.

This study showed that with a higher BMI was associated with more exercise-induced GI symptoms. This corresponds with a meta-analysis showing that some GI symptoms are more strongly associated with obesity and increasing BMI than other GI symptoms. ${ }^{20}$

The timing of the prerunning meal and snack was not associated with GI symptoms (see tables 3 and 4). On average our participants consumed their food at least 
Table 3 Comparisons between female runners with or without Gl symptoms regarding nutritional and activity features

\begin{tabular}{|c|c|c|c|c|}
\hline \multirow[b]{2}{*}{ Variable } & \multicolumn{2}{|c|}{$\begin{array}{l}\geq 1 \text { Gl symptoms during their } \\
\text { last run }\end{array}$} & \multirow[b]{2}{*}{ Test statistic } & \multirow[b]{2}{*}{ p Value } \\
\hline & Yes $n=210^{*}$ & No $n=223^{*}$ & & \\
\hline Age (year) & $36.8 \pm 11.5$ & $40.4 \pm 11.2$ & $3.32 \dagger$ & 0.00 \\
\hline $\mathrm{BMI}$ & $23.6 \pm 3.0$ & $22.7 \pm 2.7$ & $-3.13 \dagger$ & 0.00 \\
\hline Timing of prerunning meal (min) $\ddagger$ & $104.6 \pm 69.8$ & $102.4 \pm 70.3$ & $-1.32 \dagger$ & 0.19 \\
\hline Timing of prerunning snack $(\mathrm{min}) \S$ & $89.2 \pm 65.2$ & $81.6 \pm 60.6$ & $-0.48 \dagger$ & 0.63 \\
\hline \multicolumn{5}{|l|}{ Amount drink $(\mathrm{mL})$} \\
\hline $1-4 \mathrm{~h}$ before running & $304.0 \pm 263.7$ & $255.0 \pm 200.1$ & $-2.19 \dagger$ & 0.03 \\
\hline Within $1 \mathrm{~h}$ before running & $156.5 \pm 118.8$ & $146.6 \pm 110.5$ & $-0.90 \dagger$ & 0.37 \\
\hline During running & $27.5 \pm 83.0$ & $28.7 \pm 91.6$ & $0.15 \dagger$ & 0.89 \\
\hline Running on an empty stomach (n) & $15(7 \%)$ & $31(14 \%)$ & 5.201 & 0.02 \\
\hline \multicolumn{5}{|l|}{ Sport drink (n) } \\
\hline \multicolumn{5}{|l|}{$1-4 \mathrm{~h}$ before running } \\
\hline No drink & $63(30 \%)$ & $66(30 \%)$ & $0.03 \rrbracket$ & 0.98 \\
\hline Hypotonic & $132(63 \%)$ & $140(63 \%)$ & & \\
\hline Isotonic and hypertonic & $15(7 \%)$ & $17(8 \%)$ & & \\
\hline \multicolumn{5}{|l|}{ Sport drink (n) } \\
\hline \multicolumn{5}{|l|}{ Within $1 \mathrm{~h}$ before running } \\
\hline No drink & $75(36 \%)$ & $85(38 \%)$ & $2.63 \rrbracket$ & 0.27 \\
\hline Hypotonic & $123(59 \%)$ & $132(59 \%)$ & & \\
\hline Isotonic and hypertonic & $12(6 \%)$ & $6(3 \%)$ & & \\
\hline \multicolumn{5}{|l|}{ Sport drink (n) } \\
\hline \multicolumn{5}{|l|}{ During running } \\
\hline No drink & $188(90 \%)$ & $201(90 \%)$ & $2.50^{\star \star}$ & 0.29 \\
\hline Hypotonic & $16(8 \%)$ & $20(9 \%)$ & & \\
\hline Isotonic and hypertonic & $6(3 \%)$ & $2(1 \%)$ & & \\
\hline Prevalence of total Gl symptoms in general (n) & $123(59 \%)$ & $48(22 \%)$ & $62.12 \rrbracket$ & 0.00 \\
\hline Prevalence of upper Gl symptoms in general (n) & $52(25 \%)$ & $15(7 \%)$ & $26.90 \emptyset$ & 0.00 \\
\hline Prevalence of lower Gl symptoms in general (n) & $109(52 \%)$ & $46(21 \%)$ & $46.04 \eta$ & 0.00 \\
\hline \multicolumn{5}{|l|}{ Running experience $(n)$} \\
\hline$<3$ months & $26(12 \%)$ & $20(9 \%)$ & 21.439 & 0.00 \\
\hline 3-12 months & $57(27 \%)$ & $25(11 \%)$ & & \\
\hline$>12$ months & $127(61 \%)$ & $178(80 \%)$ & & \\
\hline \multicolumn{5}{|l|}{ Kilometres ran in an average week (n) } \\
\hline$<10 \mathrm{~km}$ a week & $103(49 \%)$ & $94(42 \%)$ & 2.779 & 0.43 \\
\hline 10-20 km a week & $72(34 \%)$ & $82(37 \%)$ & & \\
\hline 20-30 km a week & $28(13 \%)$ & $35(16 \%)$ & & \\
\hline$>30 \mathrm{~km}$ a week & $7(3 \%)$ & $12(5 \%)$ & & \\
\hline \multicolumn{5}{|l|}{ Aim for '2013 Marikenloop' (n) } \\
\hline $5 \mathrm{~km}$ & 91 (43\%) & 98 (44\%) & $0.02 ף$ & 0.90 \\
\hline $10 \mathrm{~km}$ & $119(57 \%)$ & 125 (56\%) & & \\
\hline \multicolumn{5}{|l|}{ 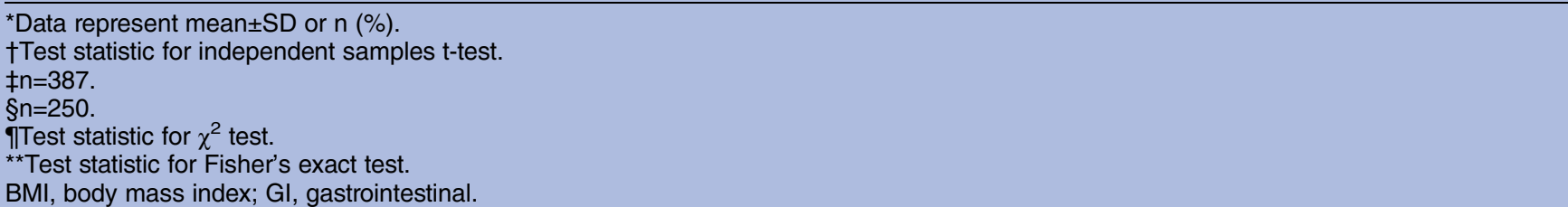 } \\
\hline
\end{tabular}

$1.5 \mathrm{~h}$ before exercising while other studies showed GI symptoms were only present when eaten within $30 \mathrm{~min}$ before exercising. ${ }^{13} 24$

We expected to see an association between isotonic and hypertonic sport drinks and GI symptoms, but this was only found when participants drank isotonic and/or hypertonic drinks during the run. This might be due to the fewer number of participants who drank isotonic and hypertonic sport drinks, which make it difficult to draw strong conclusions. There are, however, several mechanisms described that indicate that carbohydratecontaining beverages can lead to reactions in the stomach and intestine which may result in GI symptoms. $^{1} 1316303334$

One should keep in mind that comparison with data of other surveys is difficult, because of the different answer options used for detecting GI symptoms and other interpretations of those answers. Another 
Table 4 Predictor variables in the multivariable logistic regression model estimating the probability of Gl symptoms in female runners during their run

\begin{tabular}{|c|c|c|}
\hline \multirow[b]{2}{*}{ Variable } & \multicolumn{2}{|l|}{ GI symptoms } \\
\hline & OR (95\% Cl) & p-Value \\
\hline Age (year)* & $0.98(0.96$ to 1.00$)$ & 0.03 \\
\hline BMI (per 1 unit)* & $1.12(1.03$ to 1.22$)$ & 0.00 \\
\hline Timing of prerunning meal (min) & $1.00(1.00$ to 1.00$)$ & 0.59 \\
\hline Timing of prerunning snack (min) & $1.00(1.00$ to 1.00$)$ & 0.75 \\
\hline \multicolumn{3}{|l|}{ Amount drink $(\mathrm{mL})$} \\
\hline $1-4 \mathrm{~h}$ before running* & $1.00(1.00$ to 1.00$)$ & 0.20 \\
\hline Within $1 \mathrm{~h}$ before running & $1.00(1.00$ to 1.00$)$ & 1.00 \\
\hline During running & $1.00(0.99$ to 1.00$)$ & 0.23 \\
\hline Running on an empty stomach $(n)^{*}$ & $0.59(0.25$ to 1.35$)$ & 0.21 \\
\hline \multicolumn{3}{|l|}{ Sport drink (n) } \\
\hline \multicolumn{3}{|l|}{$1-4 \mathrm{~h}$ before running } \\
\hline No drink & 1 & \\
\hline Hypotonic & $0.60(0.34$ to 1.07$)$ & 0.08 \\
\hline Isotonic and hypertonic & $0.41(0.15$ to 1.11$)$ & 0.08 \\
\hline \multicolumn{3}{|l|}{ Sport drink (n) } \\
\hline \multicolumn{3}{|l|}{ Within $1 \mathrm{~h}$ before running } \\
\hline No drink & 1 & \\
\hline Hypotonic & $0.75(0.43$ to 1.31$)$ & 0.31 \\
\hline Isotonic and hypertonic & $1.54(0.46$ to 5.14$)$ & 0.48 \\
\hline \multicolumn{3}{|l|}{ Sport drink (n) } \\
\hline \multicolumn{3}{|l|}{ During running } \\
\hline No drink & 1 & \\
\hline Hypotonic & $1.32(0.46$ to 3.74$)$ & 0.61 \\
\hline Isotonic and hypertonic & $10.47(1.37$ to 80.34$)$ & 0.02 \\
\hline Prevalence of total Gl symptoms in general $(n)^{\star}$ & $4.97(3.15$ to 7.84$)$ & 0.00 \\
\hline \multicolumn{3}{|l|}{ Running experience $(n)^{*}$} \\
\hline$<3$ months & $1.62(0.74$ to 3.58$)$ & 0.23 \\
\hline $3-12$ months & $3.09(1.66$ to 5.74$)$ & 0.00 \\
\hline$>12$ months & 1 & \\
\hline \multicolumn{3}{|l|}{ Kilometres run in an average week ( $n$ ) } \\
\hline$<10 \mathrm{~km}$ a week & 1.37 (0.42 to 4.52$)$ & 0.60 \\
\hline 10-20 km a week & $1.26(0.38$ to 4.10$)$ & 0.71 \\
\hline $20-30 \mathrm{~km}$ a week & $1.24(0.36$ to 4.25$)$ & 0.73 \\
\hline$>30 \mathrm{~km}$ a week & 0 & \\
\hline \multicolumn{3}{|l|}{ Aim for '2013 Marikenloop' (n) } \\
\hline $5 \mathrm{~km}$ & 1 & \\
\hline $10 \mathrm{~km}$ & $1.30(0.80$ to 2.11$)$ & 0.30 \\
\hline
\end{tabular}

limitation was that the distances of the last runs in our study were not detected, except for the distance in the 'Marikenloop' they were training for. Furthermore, it would have been interesting to assess the associations between the predictors and the GI symptoms separately since some predictors will influence, for example, diarrhoea but not chest pain. The internet-based questionnaire has several other limitations. First, it was not validated since no short validated questionnaires for this purpose could be found. Also, it relied on the participant's memory and was therefore bias sensitive. The questions were preprogrammed, so participants could not freely tell their stories. An internet-based questionnaire is, however, low-threshold and user-friendly, which resulted in a high response (92\%) and missing values were prevented.
In conclusion, the current study demonstrates that $40 \%$ of 433 female runners training for a 5 or $10 \mathrm{~km}$ run suffered from GI symptoms during running in general and $49 \%$ had $\geq 1$ GI symptom during their last run. Predictor variables for experiencing GI symptoms during a run included lower age, less running experience, higher BMI, consuming carbohydrate-containing drinks during running compared to no drinks and experiencing GI symptoms during running in general.

Contributors DSMH, MPW, MWGNS, ALMV and JBS were involved in the conception or design of the work. All authors involved in the acquisition, analysis, or interpretation of data; drafting the work or revising it critically for important intellectual content; final approval of the version to be published; agreement to be accountable for all aspects of the work in ensuring that questions related to the accuracy or integrity of any part of the work are appropriately investigated and resolved. 
Funding This study was part of the 'Marikenloop study 2013', which was funded by ZonMw grant no. 50-50310-98-156.

\section{Competing interests None.}

Ethics approval This study was approved by the Medical Ethical Committee of the Radboud University Medical Centre, Nijmegen, the Netherlands.

Provenance and peer review Not commissioned; externally peer reviewed.

Data sharing statement No additional data are available.

Open Access This is an Open Access article distributed in accordance with the Creative Commons Attribution Non Commercial (CC BY-NC 4.0) license, which permits others to distribute, remix, adapt, build upon this work noncommercially, and license their derivative works on different terms, provided the original work is properly cited and the use is non-commercial. See: http:// creativecommons.org/licenses/by-nc/4.0/

\section{REFERENCES}

1. ter Steege RW, Kolkman JJ. Review article: the pathophysiology and management of gastrointestinal symptoms during physical exercise, and the role of splanchnic blood flow. Aliment Pharmacol Ther 2012;35:516-28.

2. Martin D. Physical activity benefits and risks on the gastrointestinal system. South Med J 2011;104:831-7.

3. Simren M. Physical activity and the gastrointestinal tract. Eur J Gastroenterol Hepatol 2002;14:1053-6.

4. Halvorsen FA, Lyng J, Ritland S. Gastrointestinal bleeding in marathon runners. Scand J Gastroenterol 1986;21:493-7.

5. Halvorsen FA, Lyng J, Glomsaker T, et al. Gastrointestinal disturbances in marathon runners. Br J Sports Med 1990;24:266-8.

6. Keeffe EB, Lowe DK, Goss JR, et al. Gastrointestinal symptoms of marathon runners. West J Med 1984;141:481-4.

7. Peters HP, Bos M, Seebregts L, et al. Gastrointestinal symptoms in long-distance runners, cyclists, and triathletes: prevalence, medication, and etiology. Am J Gastroenterol 1999;94:1570-81.

8. Rehrer NJ, Janssen GM, Brouns F, et al. Fluid intake and gastrointestinal problems in runners competing in a $25-\mathrm{km}$ race and a marathon. Int J Sports Med 1989;10:S22-5.

9. Riddoch C, Trinick T. Gastrointestinal disturbances in marathon runners. Br J Sports Med 1988;22:71-4.

10. ter Steege RW, Van der Palen J, Kolkman JJ. Prevalence of gastrointestinal complaints in runners competing in a long-distance run: an internet-based observational study in 1281 subjects. Scand J Gastroenterol 2008;43:1477-82.

11. Worme JD, Doubt TJ, Singh A, et al. Dietary patterns, gastrointestinal complaints, and nutrition knowledge of recreational triathletes. Am J Clin Nutr 1990;51:690-7.

12. Rehrer NJ, Brouns F, Beckers EJ, et al. Physiological changes and gastro-intestinal symptoms as a result of ultra-endurance running. Eur J Appl Physiol Occup Physiol 1992;64:1-8.

13. Rehrer NJ, van Kemenade M, Meester W, et al. Gastrointestinal complaints in relation to dietary intake in triathletes. Int J Sport Nutr 1992;2:48-59.

14. Ho GW. Lower gastrointestinal distress in endurance athletes. Curr Sports Med Rep 2009;8:85-91.
15. de Oliveira EP, Burini RC. Food-dependent exercise-induced gastrointestinal distress. $J$ Int Soc Sports Nutr 2011;8:1550-2783.

16. van Nieuwenhoven MA, Brouns F, Kovacs EM. The effect of two sports drinks and water on Gl complaints and performance during an 18-km run. Int $J$ Sports Med 2005;26:281-5.

17. Moses FM. The effect of exercise on the gastrointestinal tract. Sports Med 1990;9:159-72.

18. van der Werff $\mathrm{H}$, Hover $\mathrm{P}$, 'Ladies first' in Running. W.J.H. Mulier Instituut, 's-Hertogenbosch, 2011. beheer.nisb.nl/cogito/modules/ uploads/docs/42351305114516.pdf

19. Rehrer NJ, Smets A, Reynaert H, et al. Effect of exercise on portal vein blood flow in man. Med Sci Sports Exerc 2001;33:1533-7.

20. Eslick GD. Gastrointestinal symptoms and obesity: a meta-analysis. Obes Rev 2012:13:469-79.

21. Rehrer NJ, Beckers EJ, Brouns F, et al. Effects of dehydration on gastric emptying and gastrointestinal distress while running. Med $\mathrm{Sci}$ Sports Exerc 1990;22:790-5.

22. van Nieuwenhoven MA, Vriens BE, Brummer RJ, et al. Effect of dehydration on gastrointestinal function at rest and during exercise in humans. Eur J Appl Physiol 2000;83:578-84.

23. Rodriguez NR, Di Marco NM, Langley S. American College of Sports Medicine position stand. Nutrition and athletic performance. Med Sci Sports Exerc 2009;41:709-31.

24. Kondo T, Nakae $\mathrm{Y}$, Mitsui $\mathrm{T}$, et al. Exercise-induced nausea is exaggerated by eating. Appetite 2001;36:119-25.

25. Van Nieuwenhoven MA, Brummer RM, Brouns F. Gastrointestinal function during exercise: comparison of water, sports drink, and sports drink with caffeine. J Appl Physiol 2000;89:1079-85.

26. Buist I, Bredeweg SW, Bessem B, et al. Incidence and risk factors of running-related injuries during preparation for a 4-mile recreational running event. Br J Sports Med 2010;44:598-604.

27. Vittinghoff E, McCulloch CE. Relaxing the rule of ten events per variable in logistic and Cox regression. Am J Epidemiol 2007;165:710-18.

28. Vodiservice. Deskundig over sportdranken. Secondary Deskundig over sportdranken 2011. http://sport.infonu.nl/diversen/82903deskundig-over-sportdranken.html

29. Gil SM, Yazaki E, Evans DF. Aetiology of running-related gastrointestinal dysfunction. How far is the finishing line? Sports Med 1998;26:365-78.

30. van Wijck K, Lenaerts K, Grootjans J, et al. Physiology and pathophysiology of splanchnic hypoperfusion and intestinal injury during exercise: strategies for evaluation and prevention. $\mathrm{Am} \mathrm{J}$ Physiol Gastrointest Liver Physiol 2012;303:19.

31. Peters HP, van Schelven FW, Verstappen PA, et al. Gastrointestinal problems as a function of carbohydrate supplements and mode of exercise. Med Sci Sports Exerc 1993;25:1211-24.

32. Ho CW, Beard JL, Farrell PA, et al. Age, fitness, and regional blood flow during exercise in the heat. J Appl Physiol 1997;82:1126-35

33. Shi X, Horn MK, Osterberg KL, et al. Gastrointestinal discomfort during intermittent high-intensity exercise: effect of carbohydrate-electrolyte beverage. Int J Sport Nutr Exerc Metab 2004:14:673-83.

34. Rehrer NJ, Brouns F, Beckers EJ, et al. Gastric emptying with repeated drinking during running and bicycling. Int $J$ Sports Med 1990;11:238-43. 